\title{
JOINT MOBILITY CHANGES DUE TO LOW FREQUENCY VIBRATION AND STRETCHING EXERCISE*
}

\author{
J. ATHA, Ph.D., M.A., D.P.E. \& D. W. WHEATLEY, B.Sc. \\ Department of Human Sciences, Loughborough University of Technology
}

\section{INTRODUCTION}

Apart from surgical intervention and manipulation under anaesthetic there appear to be two general approaches to the improvement of joint mobility. The first of these is through exercise - usually, but not always, mechanical stretching exercise with or without external assistance. The second is through the application of therapeutic treatments such as heat, vibration and massage. Studies have been made of the mobilising effects of some of these methods, e.g. stretching exercises (Weber and Kraus, 1949; Fieldman, 1966), weight training exercises (Massey and Chaudet, 1956; Meyers, 1971), Hatha Yoga (de Vries, 1962), the exercise effects of sports participation (Skvartsov and Sermeev, 1964), exercises following the principles of proprioceptive neuromuscular facilitation (Tanigawa, 1972), relaxation exercises (Warden, 1961), vibration (Bierman, 1960), massage (Kos, 1966) and heat treatment (Kos, 1966; Grobacker and Stull, 1975).
\end{abstract}

ABSTRACT

It has been shown that fifteen minutes of locally applied cycloid vibration of low amplitude and frequency is equally as effective as a fifteen minute programme of flexibility exercises in increasing short term mobility of the hip flexors. It is suggested that this mobility change may occur as a result of improved muscle relaxation.

Comparisons between the above studies are difficult to make because of the differing experimental conditions and methods of measurement employed, and because specific comparative studies, even of related methods within one class of treatments, are rare. Consequently, it is not easy to decide if one method is better than another. No agreed guide exists to the most appropriate regimen to be adopted even in such long established practices as mobilising exercises except "the clinical experience of the physician and physiotherapist" (Johnson and Buskirk, 1974, P449). Yet such a guide would be helpful to clinicians involved in the rehabilitation of disabled persons and to sportsmen concerned with the achievement of high levels of skilled performance.

It is the purpose of this paper to examine the relative merits of two mobilising techniques that have different principles of action.

*Supported by a grant from Niagara Therapy (U.K.) Ltd.

\section{Review of the Literature}

Joint mobility is limited by the bony and fleshy masses that block movements in the end position, by the muscles, tendons, ligaments and capsules that act as ties and which are put on stretch in the limiting position, by articular pains that inhibit movement, by joint pathology, muscle viscosity, reciprocal muscle co-ordination, neuropathology, and general stress and anxiety (Billig and Loewendahl, 1949). The mobility of joints appears to be independent of physique (Laubach and McConville, 1966) and not as age dependent as is commonly assumed (Greey, 1958) though evidence of mobility peaks at different ages are reported e.g. at 14-15 years (Skvortsov and Sermeev, 1964) and at 25 years (Jervey, 1962).

Harris (1967) and Dickinson (1968) have shown that the range of motion possible in one joint action is little correlated with that in any other. Harris, who has also shown that the mobility of even protagonists and antagonists are not correlated, argues that it is no longer sensible to support a general concept of flexibility.

It follows, that if flexibility is as highly joint specific as Harris and Dickinson maintain, then any examination of flexibility must be conducted with reference to specific articulations and that inferences drawn from a study of a single joint should be generalised with reserve. At the same time it must be borne in mind that the tissues around similar joints are similar, so it should not be beyond the limits of ingenuity to develop unifying generalisations of some kind, as have Johns and Wright (1962), about their role in limiting movement.

At least two main treatment principles, apart from those underlying the lesser used techniques of massage and heat, may be identified.

The first is implicit in those exercises in which a joint is stretched to the point of extreme discomfort (Billig and Loewendahl, 1949; Stafford and Kelley, 1958) and 
may be expressed, say, as: "The development of mobility in a joint is a function of the magnitude and frequency of the imposed tolerable stretch." The validity of such a principle would tend to be supported by the studies of Weber and Kraus (1949), Greey (1958) and Fieldman (1966) but not by those of de Vries (1962).

The second principle underlies both the neuromuscular relaxation method of Warden (1962) and the proprioceptor neuromuscular facilitation method of Kabat (1965) and Knott and Voss (1968). It is not so readily summarised but may be stated, say, as: "The development of mobility is a function of the magnitude and duration of the sensory traffic that can be induced to activate central neuromuscular inhibitory responses." This same principle may also underlie the localised cycloid vibration technique of Bierman (1960) although Bierman has expressed no opinion about how vibration has its effect. It is known, that vibration acts on muscle and joint receptors particularly on the spindle afferents to produce the tonic vibration reflex, and also, given that suitable lower frequencies are used, on the Group II secondary endings to produce relaxation of the antagonists and inhibition of the monosynaptic reflex, (Rushworth and Young, 1966; Goodwin, McCloskey and Matthews, 1971; Hagbarth and Eklund, 1969; Eklund, 1971). In general this second principle would be supported by the studies of Bierman (1960), Chapman, Swezey and de Vries (1970) and Tanigawa (1972).

If such contrasting principles are identifiable then mobilising techniques in current use must not only be presumed to have different target sites but also to have different effects on different joints. An interesting feature of studies into mobilising methods reported in the literature is the almost invariable omission of references to the nature of the mechanism it is intended that they should invoke. One is therefore left to conjecture about whether their purpose is to stretch a tightened capsule, to relax an habitually tense muscle, to alter the elastic properties of a ligament or tendon, to break down minor adhesions, to alter muscle viscosity, or whatever. It seems that except in specific clinical cases mobilising techniques are believed to have constant effects irrespective of the nature of limiting structure involved.

\section{METHOD}

Two contrasting mobilising techniques were used to improve the range of movement of the hip joint in flexion. The first was a classical method involving stretching exercise, the second a relatively recently proposed method involving vibration. A third treatment, a control, was also examined. The control condition consisted of fifteen minutes of quiet seated rest.
Low frequency $(44 \mathrm{~Hz})$ vibration was provided by two Niagara Therapy (U.K.) Ltd., mains powered vibration cushions which supported the thighs and lower back of the seated subject. The peak to peak displacement amplitude of the signal was elusive, but of the order of 0.1 $\mathrm{mm}$. This level of vibration was considered to be moderately comfortable. Some subjects read during the test period.

The mobilising programme consisted of a warm-up exercise followed by four stretching exercises of the active-sustained type viz:-

(a) Standing: continuous spot running followed by crouch jumping

(b) Astride standing: head pressing to alternate knees

(c) Tuck sitting, alternate heel support: single leg stretching

(d) Rear lunge, with toe rest: calf and leg stretching

(e) Crouch, ankles held: double knee stretching to pike standing

The exercises were repeated ten times. Bouncing was not permitted. The extreme position of acute discomfort was held for two to five seconds, and was followed by a few seconds of complete relaxation.

Forty-two healthy young adult males randomly and independently sampled from the undergraduate and post-graduate population of the University took part in the study. All subjects were given the three mobilising treatments, one on each of three successive days. The sequence of treatments was randomised, except that an equal number of subjects received each possible combination of treatment orders. All treatments lasted fifteen minutes. In addition a record was made of each subject's age, height, weight and dactylion height - i.e. the distance of the tip of the third finger to the ground in erect standing.

Before and after each treatment session hip flexion mobility was measured using a modified sit-and-reach test, (Atha and Wheatley, 1976), which yielded a measure of hip flexion in centimeters of reach, to the nearest half centimeter.

Hip flexion was chosen as the criterion measure because its range of movement is limited not by unyielding bony or fleshy obstructions as is, say, the knee in flexion or the elbow in extension, but by potentially extensible musculo-tendinous ties. Moreover hip flexion is a classical test that has been shown to give reliable results.

A warm-up of four practice trials was given before each test session. This was followed by three test trials. All test trials were recorded but only the best counted as the criterion score. 


\section{RESULTS}

The general characteristics of the sample studied are shown in Table I from which it may be seen that the subjects were young men of more or less normal build. The last entry in the table, dactylion height, provides the reference zero of the assumed true scale of measurement of the dependent variable, although for convenience in practice an arbitrary zero was used.

Table I

Age, Height, Weight and Dactylion Height of the Sample

\begin{tabular}{|c|c|c|c|c|}
\hline & \multicolumn{4}{|c|}{ DACTYLION } \\
\hline & $\begin{array}{l}\text { AGE } \\
\text { (yrs) }\end{array}$ & $\begin{array}{l}\text { HEIGHT } \\
(\mathrm{cm})\end{array}$ & $\begin{array}{l}\text { WEIGHT } \\
(\mathrm{kg})\end{array}$ & $\begin{array}{l}\text { HEIGHT } \\
(\mathrm{cm})\end{array}$ \\
\hline $\bar{x}$ & 23.1 & 176.5 & 68.4 & 65.5 \\
\hline S.D. & 3.0 & 6.9 & 8.6 & 4.0 \\
\hline RANGE & $\begin{array}{l}18.0- \\
33.8\end{array}$ & $\begin{array}{l}158.8- \\
192.8\end{array}$ & $\begin{array}{l}52.7- \\
88.0\end{array}$ & $\begin{array}{l}56.5- \\
74.0\end{array}$ \\
\hline
\end{tabular}

To establish the reliability of the measurements Pearson product-moment correlations were calculated between the criterion test score and the combined remaining two scores in each series of pre- and post-treatment tests (Table II). Examination of this table shows that the coefficients are high, ranging from 0.94 to 0.99 , and unequivocally support the view that all measurements are acceptably reliable.
Table II

Reliability coefficients for all test sessions

\begin{tabular}{llll} 
& Day 1 & Day 2 & Day 3 \\
Pre-treatment & 0.980 & 0.989 & 0.944 \\
Post-treatment & 0.991 & 0.992 & 0.990 \\
\hline
\end{tabular}

The means and standard deviations of the mobility measurements made on all subjects are presented in Table III.

If the pre-treatment mobilities of all groups are compared they can be seen to be generally alike, apart from the Day 1 results of the control and vibration groups which appear to be a little lower than the rest. These results, therefore, provide a good general basis for the remainder of the analysis.

Examination of the post-treatment means shows them to be higher in every instance than the pre-treatment means, while their associated variances are in almost every instance smaller. The relative magnitude of these changes may be better appreciated if the differences between these means before and after treatments are calculated (Table IV), and plotted (Figure 1).

From the marginal values in Table IV it can be seen that the average improvement for all treatment groups on Day $1(3.0 \mathrm{~cm})$ is greater than it is on either of the following two days. It can also be seen that the average

\section{Table III}

Means and standard deviations of hip flexion mobility measurements ${ }^{*}$ recorded over three days on forty-two adult males before and after a period of controlled rest, cycloid vibration and mobilising exercise

\begin{tabular}{|c|c|c|c|c|c|c|c|}
\hline & & \multicolumn{2}{|c|}{ CONTROL } & \multicolumn{2}{|c|}{ VIBRATION } & \multicolumn{2}{|c|}{ EXERCISE } \\
\hline & & PRE & POST & PRE & POST & PRE & POST \\
\hline DAY 1 & $\begin{array}{l}\bar{x} \\
\text { SD } \\
\text { RANGE }\end{array}$ & $\begin{array}{l}26.1 \\
(7.0) \\
16.0- \\
39.0\end{array}$ & $\begin{array}{l}28.7 \\
(6.9) \\
19.5- \\
41.5\end{array}$ & $\begin{array}{l}26.7 \\
(7.3) \\
12.5- \\
37.0\end{array}$ & $\begin{array}{l}29.4 \\
(6.7) \\
17.0- \\
41.0\end{array}$ & $\begin{array}{l}29.5 \\
(4.1) \\
20.0- \\
35.0\end{array}$ & $\begin{array}{l}33.1 \\
(3.2) \\
24.0- \\
37.5\end{array}$ \\
\hline DAY 2 & $\begin{array}{l}\bar{x} \\
\text { SD } \\
\text { RANGE }\end{array}$ & $\begin{array}{l}29.9 \\
(5.8) \\
15.5- \\
40.5\end{array}$ & $\begin{array}{l}31.4 \\
(5.5) \\
19.0- \\
42.0\end{array}$ & $\begin{array}{l}30.4 \\
(6.3) \\
20.0- \\
42.0\end{array}$ & $\begin{array}{l}32.9 \\
(6.5) \\
22.0- \\
44.0\end{array}$ & $\begin{array}{l}28.1 \\
(5.9) \\
20.5- \\
39.0\end{array}$ & $\begin{array}{l}30.5 \\
(4.7) \\
23.5- \\
39.5\end{array}$ \\
\hline DAY 3 & $\begin{array}{l}\bar{x} \\
\text { SD } \\
\text { RANGE }\end{array}$ & $\begin{array}{l}29.9 \\
(5.1) \\
19.5- \\
36.0\end{array}$ & $\begin{array}{l}30.8 \\
(4.9) \\
21.5- \\
36.0\end{array}$ & $\begin{array}{l}29.1 \\
(5.4) \\
17.0- \\
36.5\end{array}$ & $\begin{array}{l}31.5 \\
(5.4) \\
24.0- \\
37.5\end{array}$ & $\begin{array}{l}30.2 \\
(8.3) \\
15.5- \\
43.0\end{array}$ & $\begin{array}{l}32.8 \\
(8.0) \\
20.5- \\
46.0\end{array}$ \\
\hline
\end{tabular}

* in centimetres 
Table IV

Changes in hip flexion mobility * following three treatment programmes

$\begin{array}{llllll} & & \text { DAY } 1 & \text { DAY } 2 & \text { DAY } 3 & \text { OVERALL } \\ \text { CONTROL } & \bar{X} & 2.6 & 1.5 & 0.9 & 1.7 \\ & \text { SD } & (1.1) & (1.0) & (1.1) & (1.3) \\ \text { VIBRATION } & \text { RANGE } & 1.0-4.0 & 0.5-3.5 & -1.0-3.0 & -1.0-4.0 \\ & \bar{X} & 2.7 & 2.5 & 2.4 & 2.5 \\ & \text { SD } & (1.5) & (1.6) & (2.0) & (1.7) \\ \text { EXERCISE } & \text { RANGE } & 0.5-5.5 & 0.0-5.5 & 0.0-8.5 & 0.0-8.5 \\ & \bar{X} & 3.6 & 2.4 & 2.6 & 2.9 \\ & \text { SD } & (2.4) & (1.6) & (1.2) & (1.9) \\ \text { OVERALL } & \text { RANGE } & 0.0-8.5 & 0.5-5.5 & 1.0-5.0 & 0.0-8.5 \\ & \bar{X} & 3.0 & 2.1 & 2.0 & \\ & \text { SD } & (1.8) & (1.4) & (1.5) & \\ * & \text { RANGE } & 0.0-8.5 & 0.0-5.5 & -1.0-8.5 & \end{array}$

improvement made on the three days by the two treatment groups combined $(2.7 \mathrm{~cm})$ is higher than for the controls $(1.7 \mathrm{~cm})$.

At the same time examination of the body of the table shows that on the first day the control groups made gains very similar to those of the treatment groups. It is not until the second and third days that the dominance of the treatment groups begins to show itself. In view of the changes recorded by the control groups particularly on the first day, the standardised measurement procedures adopted to establish a stable mobility baseline cannot be considered to have been entirely successful. Subsequently the much smaller changes recorded, e.g. only $0.9 \mathrm{~cm}$ on Day 3, suggests the procedures did eventually achieve their aim of eliminating from the treatment results those readily obtained gains possible, after a period of inactivity, from the dissipation of transitory stiffness.

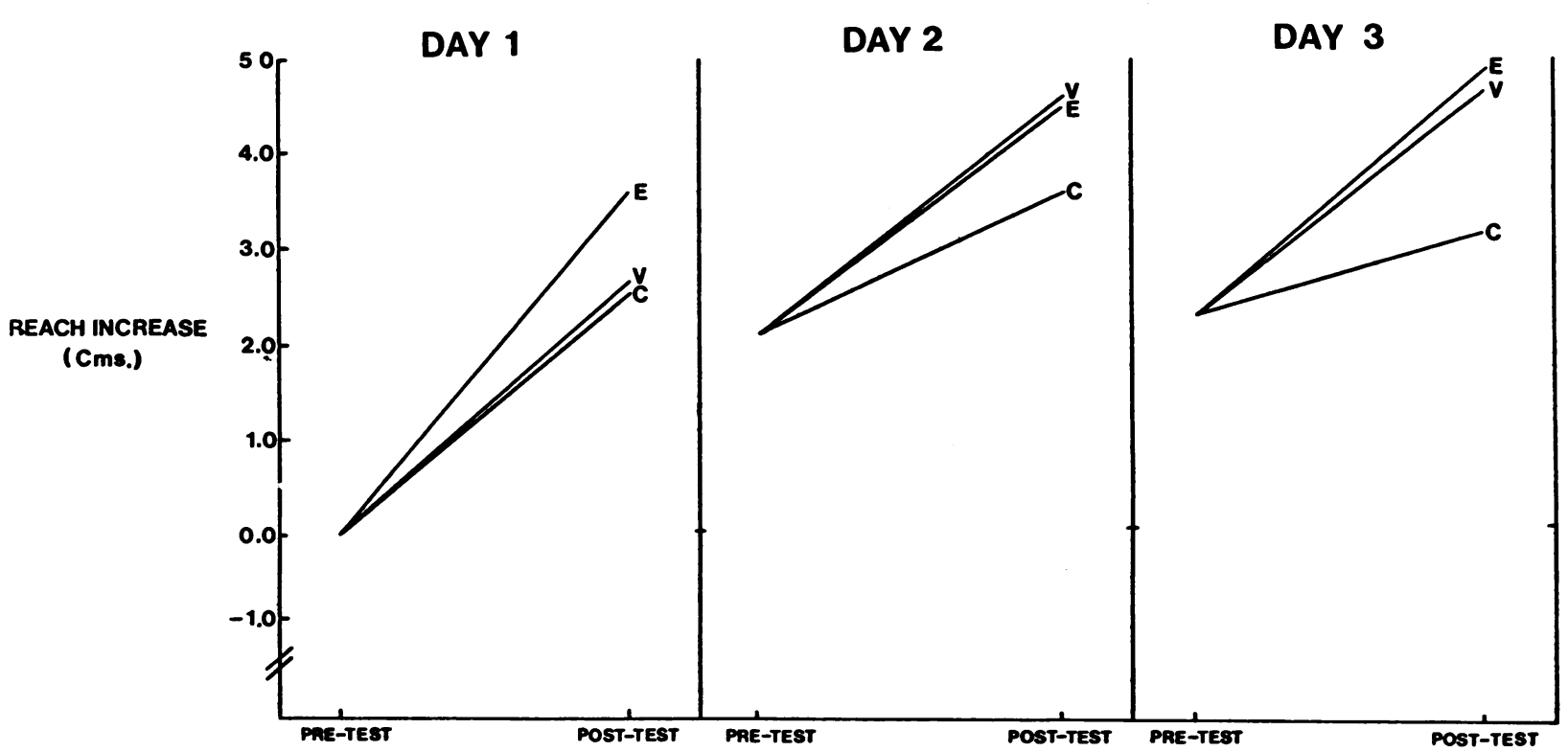

FIGURE 1; Mean increases in muscle extensibility scores of forty-two adult males on three days following control testing (C), cycloid vibration (V), and flexibility exercise programme (E). 
From Figure 1 the superiority of both vibration and exercise over the control condition, after Day 1 , is easily observed. At the same time the similarity of the effects produced by the two experimental treatments themselves is also clearly demonstrated.

The above results were tested for statistical significance using a repeated measures analysis of variance. Two simple questions about the treatments were examined.

a) Do exercise and vibration improve mobility? b) If so, do they do so equally?

Analogous questions were asked about the effects of testing on different days.

a) Are the results obtained on Day 1 different from those obtained on Days 2 and 3?

b) Are Day 2 and Day 3 results different from each other?

Components of variance associated with each of these questions were calculated using relevant linear contrasts, and these are included in the Analysis of Variance summary table (Table V).

Table V

Analysis of Variance: the effects of vibration and exercise on hip flexion mobility

\begin{tabular}{|c|c|c|c|c|}
\hline SOURCE OF VARIANCE & d.f. & SS & MS & $\mathbf{F}$ \\
\hline BETWEEN TREATMENTS & 2 & 30.52 & 15.26 & - \\
\hline $\begin{array}{l}\text { CONTROL } \vee \text { EXPERIMENTAL VARIABLES } \\
\text { CYCLOID VIBRATION } \text { EXERCISE }\end{array}$ & $\begin{array}{l}1 \\
1\end{array}$ & $\begin{array}{r}27.67 \\
2.85\end{array}$ & $\begin{array}{r}27.67 \\
2.85\end{array}$ & $\begin{array}{l}10.50^{* *} \\
1.08\end{array}$ \\
\hline $\begin{array}{l}\text { BETWEEN DAYS } \\
\text { DAY } 1 \text { vDAYS } 2 \text { and } 3 \\
\text { DAY } 2 \text { vDAY } 3\end{array}$ & $\begin{array}{l}2 \\
1 \\
1\end{array}$ & $\begin{array}{r}24.11 \\
23.53 \\
0.58\end{array}$ & $\begin{array}{r}12.06 \\
23.53 \\
0.58\end{array}$ & $\begin{array}{l}- \\
8.91^{* *} \\
0.22\end{array}$ \\
\hline DAYS X TREATMENTS & 4 & 7.06 & $\begin{array}{ll}1.77 & 0.67\end{array}$ & 0.67 \\
\hline REPLICATIONS & 117 & 308.34 & 2.64 & - \\
\hline TOTAL & 125 & 370.03 & - & - \\
\hline
\end{tabular}

Examination of the $F$-ratios in Table $V$ confirms that the Day 1 results are significantly different from those recorded on Days 2 and 3, but that the Day 2 and Day 3 results are very similar. As the Day-by-Treatment interaction term is not significant it may be concluded that notwithstanding the mean differences between the results on the first as compared with the other days the general pattern of results is the same irrespective of the day on which they were recorded.

The highly significant F-ratio associated with the contrast between the control condition and the experimental treatments leads unequivocally to the conclusion that both vibration and exercise, as already surmised, have mobilising effects that cannot be attributed to chance or to the mobilising effects of any test procedure. However the non-significant $F$-ratio associated with the second question clearly suggests that neither of the two treatments is more effective in joint mobilising than the other.
Supplementary analysis

In a repeated measures experiment the presence of significant carry-over effects from one treatment to the next may invalidate results ( $\mathrm{Li}, 1964)$. It had been anticipated from an initial study of the effects of repeated measurements on hip flexion that such carry-over effects would be negligible. However, the significant difference found between Day 1 and the two subsequent days meant that this assumption could no longer be fully justified. The non-significant Day-by-Treatment interaction term could, of course, be used as evidence that carry-over effects had not seriously influenced the results, nevertheless it was decided to reanalyse the data for the second two days only, and to re-organise them in such a way that any carry-over effects present would have most chance of being revealed. This was done by partitioning the data for each treatment into sets accord ing to the treatment received the preceding day. 
Table 6

Data partitions according to the treatment received the preceding day

\begin{tabular}{|c|c|c|c|c|c|c|}
\hline & $\operatorname{coN}$ & TROL & VIBI & ATION & EXE & RCISE \\
\hline & $\begin{array}{l}\text { DAY } \\
2\end{array}$ & 3 & $\begin{array}{l}\text { DAY } \\
2\end{array}$ & 3 & $\begin{array}{l}\text { DAY } \\
2\end{array}$ & 3 \\
\hline $\begin{array}{l}\text { after Control } \\
\text { after Vibration } \\
\text { after Exercise }\end{array}$ & $\begin{array}{l}\overline{1.5} \\
1.5\end{array}$ & $\begin{array}{l}\overline{1.3} \\
0.7\end{array}$ & $\begin{array}{l}2.3 \\
\overline{2.5}\end{array}$ & $\begin{array}{l}2.3 \\
2.4\end{array}$ & $\begin{array}{l}2.6 \\
2.3 \\
-\end{array}$ & $\begin{array}{l}2.4 \\
2.9 \\
-\end{array}$ \\
\hline OVERALL & 1.5 & 1.0 & 2.4 & 2.4 & 2.5 & 2.7 \\
\hline COMBINED MEANS & 1.3 & & 2.4 & & 2.6 & \\
\hline
\end{tabular}

The results of this partitioning are presented in Table VI where the entries in each cell represent the mean changes produced by the column treatment when preceded on the previous day by the row treatment.

Scrutiny of this table reveals no inconsistencies. The main effects are extremely constant over day and treatment combinations. Indeed these results support even more strongly the tentative conclusions already suggested.

\section{CONCLUSIONS}

The preceding results lead to the following conclusions:-

1. Low frequency vibration can improve joint mobility.

2. As short term mobilising techniques vibration and classical mobilising exercises involving activesustained stretching are equally effective.

3. The effects of a single fifteen minute mobilising treatment can persist for twenty-four hours.

\section{DISCUSSION}

Any discussion of either the practical or theoretical implications of the above findings must be constrained by four considerations:

1. The joint studied was one in which musculo-tendinous ties limited movement and the results and conclusions should be considered to be relevant only to such joint actions.

2. Short term mobility only was measured, and no extrapolation to long term mobility changes is permissible.

3. The population sampled, and to which the results refer, was of normal healthy young adult males. Implications that similar effects would be found with other populations cannot be assumed.
4. Although the relative merits of exercise and vibration may be held to be fairly represented by the two fifteen minute treatments adopted inevitably arbitrary decisions were taken regarding the selection of treatment frequency, rate, intensity, duration, displacement amplitude etc. It is entirely possible that a different selection of these factors might have produced different results.

Within the above constraints the results may be said to be broadly in harmony with the findings on exercise by Fieldman (1966) and others, and about vibration by Bierman (1960). That exercise and vibration both improve mobility is interesting, but even more interesting is the finding that they do so equally, so that an average subject seated at rest on a vibrating cushion gains about the same mobility increases as if he had undertaken a strenuous programme of flexibility exercise.

subject seated at rest on a vibrating cushion gains the same mobility increases as if he had undertaken a strenuous programme of flexibility exercise.

In practice of course exercise will usually be preferred because of the general concomitant benefits it can bestow, and no doubt also because of cost; but situations could arise in which techniques such as vibration would be invaluable, for instance, with the non-ambulatory patient, or where some therapeutic treatment that is not labour intensive is required. Its usefulness in such situations would, of course, depend upon its long term effectiveness and these long term effects have not been determined.

The similarity of the results produced by these two quite different techniques is important, however, not so much because of the practical issues involved but more because of the theoretical implications it raises. If vibration has the same order of effect as exercise how can it be argued that the primary function of mobilising treatments is to stretch shortening connective tissue (Allman, 
1974, P122). The question must be raised as to what yields? and why?

Given that there is no prior joint pathology and that the mobility changes produced are minimal, mobility may conceivably increase in the short term as a result of:

a) stretching of joint ligaments,

b) stretching of the joint capsule,

c) stretching of connective tissue in muscles and tendons,

d) relaxation,

e) increases in the subject's tolerance to the pain of stretching, or

f) alterations in the level of the threshold stimulus invoking pain.

It is not easy to support the first three alternatives. Meyers (1971) was unable to produce changes in ligament lengths even with heavy weight-assisted stretching exercises continued over a ten week period so it is unlikely that less strenuous exercises performed on only one occasion would do more. The joint capsule and joint ligaments cannot be held to have been subjected to any real stretch in the exercise programme administered. All these fit young men could have flexed their hip joints much further than they did during the exercises simply by flexing their knees to take the strain off the hamstrings. A stretch was, of course, placed on the muscles and tendons by the exercises so connective tissue stretching might have occurred here. On the other hand vibration which was highly effective as a mobiliser can hardly be held to have stretched any tissues, so mobility cannot have been improved by this means.

It is perhaps easier to argue that, in so far as pain can inhibit a subject's efforts during maximum stretching, alterations in the stretch required to invoke pain by altering either pain thresholds or the joint position at which pain is sensed could result in an increase in apparent mobility. In view of the link that exists between increases in proprioceptive impulses and decreases in perceived pain, some mechanism that acts by proprioceptive feedback potentiation of inhibition of pain could exist. However this idea is less persuasive because it is less simple that the final alternative, viz. increased muscle relaxation.

Stretching and vibration have well known effects on muscle and tendon receptor organs. Even though the frequency and peak to peak displacement amplitude of the vibrations used in this study were not enough (Eklund and Hagbarth, 1966) to invoke an optimum tonic vibration reflex they were clearly able to illicit some response. The frequencies used were also in the range to produce some inhibition of the Group II afferents (Eklund, 1971), so it is reasonable to suppose that during vibration reflex pathways were subjected to a barrage of afferent traffic for a sustained period. As the stretch reflex has transcortical connections (Marsden, Merton and Morton, 1972) it is also possible that some re-setting of the tonicity of the muscle may have occurred, i.e. increased relaxation. Why such effects should persist after 24 hours is, however, not explained. It is thus suggested, albeit tentatively, that the primary mechanism involved in increasing short term mobility in - joints limited by musculo-tendinous ties, is a re-setting, under conditions of excessive proprioceptor activity, of some centrally controlled level of muscle relaxation.

\section{SUMMARY}

It has been shown that fifteen minutes of locally applied cycloid vibration of low amplitude and frequency is equally as effective as a fifteen minute programme of flexibility exercises in increasing short term mobility of the hip flexors. It is suggested that this mobility change may occur as a result of improved muscle relaxation.

\section{BIBLIOGRAPHY}

Allman, F. J., 1974, 'Conditioning for Sports', Ch 6 in Ryan A. J. and Allman F. J., 1974, Sports Medicine London: Academic Press.

Atha, J. and Wheatley, D. J., 1976, The mobilising effects of treatment on Hip Flexion, British Journal of Sports Medicine. 10, 00-00.

Bierman, W., 1960, 'Influence of Cycloid Vibration Massage on Trunk Flexion', American Journal of Physical Medicine, 39, 219-224.

Billig, G. E. and Loewendahl, E., 1949, Mobilization of the Human Body. (Stanford: Stanford University Press).

Chapman, E. A., Swezey, R. and de Vries, H. A. 1970, 'The effect of low level muscle action potentials upon the measurement of joint stiffness', Paper to A.A.H.P.E. 8th Convention. 
de Vries, H. A., 1962, 'Evaluation of static stretching procedures for the improvement of flexibility', Research Quarterly, 33, 222-229.

Dickinson, R. V., 1968, 'The Specificity of Flexibility', Research Quarterly, 38, 792-794.

Eklund, G., 1971, 'Muscle Vibration in Man: an amplitude dependent inhibition inversely related to muscle length', Acta.Physiol.Scand. 83, 425-426.

Fieldman, H., 1966, 'Effects of Selected Extensibility Exercises on the Flexibility of the Hip Joint', Research Quarterly, 37, 326-331.

Greey, G. W. 1955, 'A Study of the Flexibility of Five Selected Joints of Adult Males, Ages 18 to 71', Unpublished Ph.D. dissertation, Ann Arbor. Michigen.

Grobaker, M. R. and Stull, G. A., 1975, 'Thermal Applications as a determiner of joint flexibility', American Correction Therapy Journal, 29, 3-8.

Harris, M. L., 1967, 'A factor analysis of flexibility', Ph.D. Dissertation. University of Wisconsin.

Hagbarth, K. E. and Eklund, G., 1969, 'The Muscle vibrator - a useful tool in neurological therapeutic work', Scand.J.Rehab.Med. 1, 26-34, 1969.

Jervey, A. A., 1962, 'A study of the flexibility of selected joints in specified groups of adult females'. Unpublished Ph.D. Dissertation, University of Massachusetts.

Johns, R. J. and Wright, V., 1962, 'Relative Importance of Various tissues on Joint Stiffness', Journal of Applied Physiology, 17, 824-828.

Johnson, W. R. and Buskirk, E. R., 1974, (ed.) Science and Medicine of Exercise and Sport, (London: Harper Row).

Kabat, H., 1965, 'Proprioceptive Facilitation and Therapeutic Exercise', Ch. 13 in Licht, S. (ed.) Therapeutic Exercise, (Licht: New Haven).

Knott, M. and Voss, D. E., 1968, 'Proprioceptive Neuromuscular Facilitation', 2nd ed. (New York: Harper \& Row).

Kos, B., 1966, 'The influence of warming up, a hot shower and massage upon the breadth of lumbar movement', (France). Acta. Univ. Catholinae Gymnike 2.

Laubach, L. L. and McConville, J. T., 1966, 'Relationships between flexibility, Anthropometry and the Somatotype of College Men', Research Quarterly, 37, 241-251.

Massey, B. H. and Chander, N. L., 1956, 'Effects of Systematic, Heavy resistive exercise on range of joint movement in young male adults', Research Quarterly, 27, 1956.

Marsden, C. D., Merton, P. A. and Morton, H. B., 1972, 'Servo-action in Human Voluntary Movement', Nature, 238, 140-143.

Meyers, E. J., 1971, 'Effect of selected exercise variables on Ligament Stability and Flexibility of the Knee', Research Quarterly, 42, 411-422.

Rushworth, G. and Young, R. R., 1966, 'The Effect of vibration on tonic and phasic reflexes in man', J.Physiol., 185, 630-641.

Skvortsov, B. L. and Sermeev, B. V., 1964, 'Joint mobility compared in young Swimmers', Trans. from Russia in Rev.Analyt.Educ.Phys.Sport, 7, 1-92.

Tanigawa, M. C., 1972, 'Comparison of the Hold-Relax procedure and Passive Mobilisation on Increasing Muscle Length', Physical Therapy, 52, 725-735. 
Warden, C., 1962, 'A study of the effects of relaxation on selected elements of skill', Unpublished M.S. Thesis, South College, Massachusetts.

Weber, S. and Kraus, H., 1949, 'Passive and Active Stretching of Muscles', Physical Therapy Review, 29, 407-410.

Wright, V., and Plunkett, T. C., 1966, 'Rheumatology and Joint Stiffness', Remedial Gymnastics and Recreational Therapy, 42, 13-16. 